\title{
Efficacy of Preoperative Intramuscular Testosterone Therapy for Micro-phallic Hypospadias
}

\author{
MD. AYUB ALI, ${ }^{1}$ PARITOSH KUMAR PALIT, ${ }^{2}$ MD. HASANUZZAMAN ${ }^{3}$
}

\begin{abstract}
Background: Surgical corrections of genital defects were formally proposed when the size of the penis is sufficient to permit easy surgical repair. In micro phallic hypospadias, temporary stimulation with testosterone either topical or parenteral to enlarge the penile size has been reported. The aim of this study was to evaluate the efficacy of preoperative intramuscular testosterone therapy in micro phallic hypospadiac patients.

Methodology: This prospective interventional study was carried out in the division of pediatric surgery, Dhaka Shishu (Children) Hospital. A total of 70 boys having micro phallic hypospadias were included in the study from July 2014 to December 2017. All patients received 3 dose of IM testosterone $(2 \mathrm{mg} / \mathrm{kg})$ at 1 month interval. Alteration of penile length, glans width and the adverse effects of testosterone therapy were recorded. Data were analyzed by using SPSS version 22.

Results: The mean length of penis before treatment was $2.61 \pm 0.57 \mathrm{~cm}$, and after intramuscular testosterone was $3.93 \pm 0.39 \mathrm{~cm}$, which is statistically significant ( $p<0$ .05). The mean glans width before treatment was $1.09 \pm 0.18 \mathrm{~cm}$ and after treatment was $1.62 \pm 0.11 \mathrm{~cm}(p<0.05)$. Few adverse effect were noted.

Conclusion: Significant penile growth was observed with less adverse effects after using intramuscular testosterone. Hormone therapy preceding surgical correction of micro phallic hypospadias improves aesthetic and functional qualities of the penis.
\end{abstract}

Key Words: Hypospadias, Testosterone, Micro phallus.

\section{Introduction}

Hypospadias can be defined as an arrest in normal development of the urethra, foreskin, and ventral aspect of the penis. Hypospadias is one of the most common congenital anomalies, occurring in approximately 1 in 125 live male births. ${ }^{1}$ According to available data, a small penis in hypospadias is a result of fetal testosterone insufficiency or lack of scrotal fold receptivity during fetal life. ${ }^{2}$

A subgroup of boys with hypospadias, especially proximal cases, has been described as having a "significantly smaller than usual" penis in the context

1. Resident Surgeon \& Assistant Professor, Division of Pediatric Surgery, Dhaka Shishu (Children) Hospital, Dhaka

2. Associate Professor, Department of Pediatric surgery, Shaheed Suhrawardy Medical College, Dhaka

3. Registrar, Department of Pediatric surgery, Shaheed Suhrawardy Medical College, Dhaka

Correspondence: Dr. Md. Ayub Ali, Resident Surgeon \& Assistant Professor, Division of Pediatric Surgery, BICH \& Dhaka Shishu (Children) Hospital, Mobile: 01711143286, E-mail: ayub.ali.dhs@gmail.com Received: 15-01-2019 of selecting patients for preoperative androgen therapy. Others characterized boys with hypospadias as micro phallic based on penile length $<2$ standard deviations (SD) from normal $(3.5 \mathrm{~cm})$, although accurately determining stretched penile length can be difficult in those proximal cases with ventral curvature and abnormal skin attachments from penoscrotal transposition. Glans size potentially is more readily measured, with several studies reporting circumferences in children with hypospadias selected for androgen stimulation. ${ }^{3}$

Micro phallic hypospadias is more common in severe hypospadias. Severe hypospadias includes those with urethral opening on the shaft of penis or on the scrotum or perineum. Between 1968 and 1990, the incidence of severe hypospadias has increased from 1.1 to 2.7 per 10,000 live births and by 1993 to 5.5 severe cases per 10,000 live births per year. ${ }^{4}$

The lack of hard scientific data, results in the use of empirical judgment when the surgeon confronts with 
a hypospadiac micro phallic case. Delaying surgical repair until the phallus is of suitable size or pretreatment with hormones and proceeding with early repair is the matter of concern. Surgeons who delay surgery usually do so based on the lack of compelling evidence that endocrine therapy is truly beneficial. It is a matter of concern that pre pubertal androgens may be detrimental. In contrast, surgeons who proceed with hormonal treatment and early surgery argue that delaying the operative procedure results in undue and avoidable psychological stress to the infant and parents. ${ }^{5}$

It has been proposed that better surgical conditions are obtained when hormones are used prior to hypospadias surgery, temporarily increasing penile length and glans circumference, favoring better local skin conditions and reducing surgical complications. Different hormones have been proposed: human chorionic gonadotropin (HCG), dihydrotestosterone (DHT) or testosterone. However, there are divergences about the hormone therapy of choice, time of use, appropriate dose, and means of application (topical or perenteral). ${ }^{6}$

If the physician chooses to use testosterone he/she will face two alternative treatment methods. One can use testosterone propionate cream $2 \%$ applied to the penile shaft 3 times daily for 3 weeks or parenteral 2 $\mathrm{mg} / \mathrm{kg}$ testosterone ethanate intramuscularly 3 doses 1 month interval. ${ }^{5}$

So, considering the above mentioned facts, present study was undertaken to see the efficacy of intramuscular testosterone therapy in micro phallic hypospadias patients.

\section{Materials and methods}

This was a prospective interventional study done in Dhaka Shishu (Children) Hospital. All patients presented with micro phallic hypospadias from July 2014 to December 2017 were included in this study. All patients received 3 dose of intramuscular steroid ( $2 \mathrm{mg} / \mathrm{kg}$ body weight) at 1 month interval. Ethical permission was taken from hospital ethical committee. Data regarding penile size, glans width and adverse effects of testosterone were recorded.
Data were analyzed using SPSS 22 software. Paired $t$ test was used to detect statistical significance.

\section{Results}

The mean age of participants was $34.86 \pm 15.04$ months (6 months to 60 months). Posterior hypospadias was most common (62.9\%).

Before treatment, the mean length of penis was $2.61 \pm 0.57 \mathrm{~cm}$. After $1^{\text {st }}$ follow up, the penile length

\section{Types of Hypospadias}

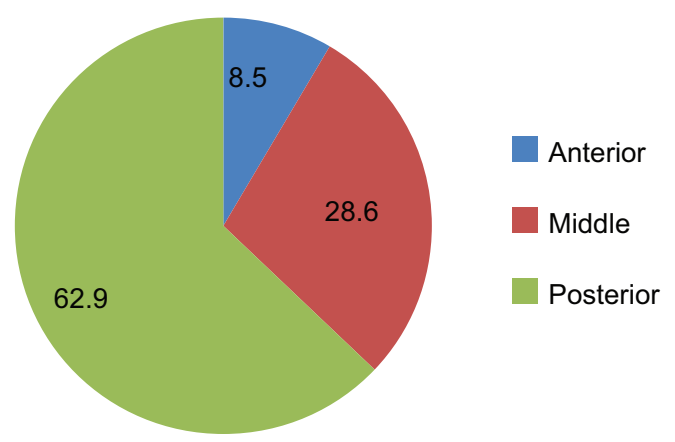

Fig.-1: Types of hypospadias

was increased and the mean was $2.86 \pm 0.50 \mathrm{~cm}$, after $2^{\text {nd }}$ follow up $3.49 \pm 0.57 \mathrm{~cm}$ and after $3^{\text {rd }}$ follow up $3.93 \pm 0.39 \mathrm{~cm}$ [Fig-2].

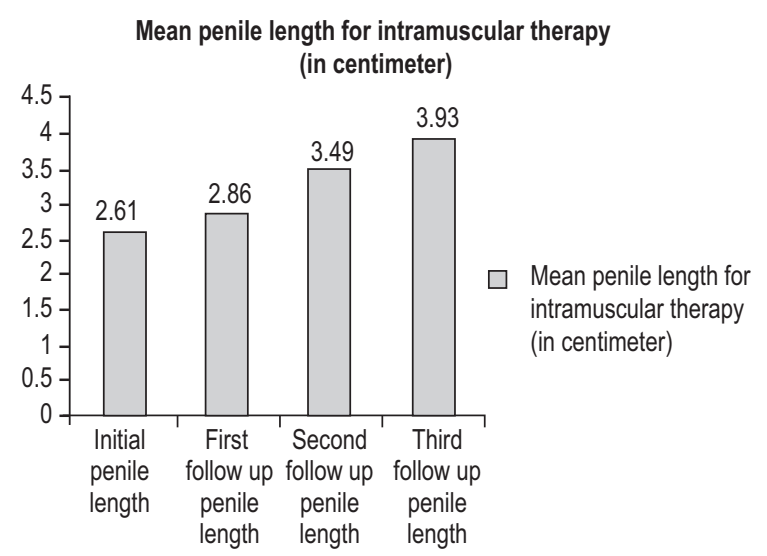

Fig.-2: Alteration of penile length

Table I

Comparison of penile length before and after intramuscular testosterone therapy

\begin{tabular}{lccc}
\hline $\begin{array}{l}\text { Penile length } \\
\text { (In centimeters) }\end{array}$ & $\begin{array}{c}\text { Before intramuscular } \\
\text { testosterone therapy }(n=70)\end{array}$ & $\begin{array}{c}\text { After intramuscular } \\
\text { testosterone therapy }(n=70)\end{array}$ & P value \\
\hline Mean \pm SD & $2.61 \pm 0.57$ & $3.93 \pm 0.39$ & 0.0001 \\
\hline
\end{tabular}

Penile length increased significantly after intramuscular testosterone therapy as $p<0.05$ (obtained from paired sample t test) [Table-I]. 
Table II

Comparison of glans width before and after intramuscular testosterone therapy

\begin{tabular}{lccc}
\hline $\begin{array}{l}\text { Glans width } \\
\text { (In centimeters) }\end{array}$ & $\begin{array}{c}\text { Before intramuscular } \\
\text { testosterone therapy }(\mathrm{n}=70)\end{array}$ & $\begin{array}{c}\text { After intramuscular } \\
\text { testosterone therapy }(\mathrm{n}=70)\end{array}$ & P value \\
\hline Mean \pm SD & $1.09 \pm 0.18$ & $1.62 \pm 0.11$ & 0.0001 \\
\hline
\end{tabular}

Glans width increased significantly after intramuscular testosterone therapy as $p<0.05$ (obtained from paired sample t test) [Table-II]

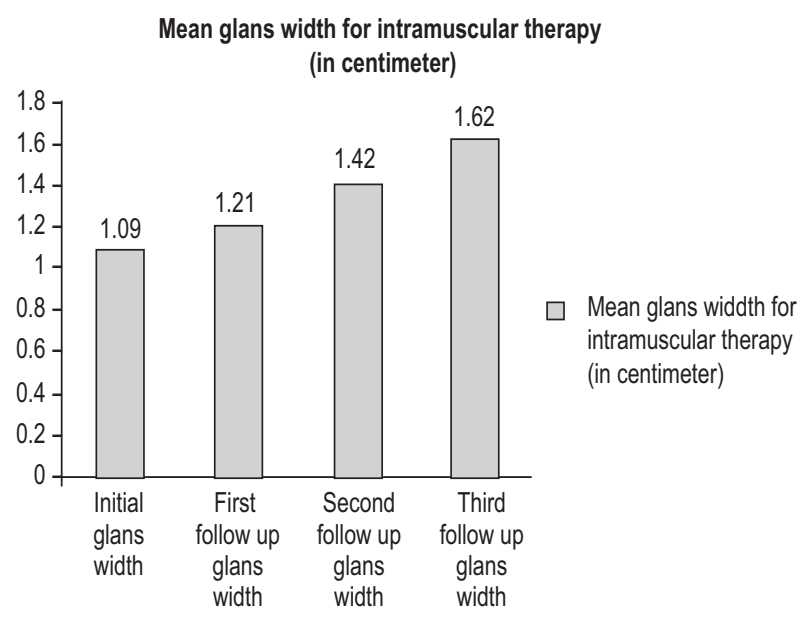

Fig.-3: Mean glans width (cm) of patients

Before treatment, the mean glans width of 70 patients was $1.09 \pm 0.18 \mathrm{~cm}$. After $1^{\text {st }}$ follow up, the glans width was increased and the mean was $1.21 \pm 0.14 \mathrm{~cm}$, after $2^{\text {nd }}$ follow up, the mean became $1.42 \pm 0.17 \mathrm{~cm}$ and after $3^{\text {rd }}$ follow up it was $1.62 \pm 0.11 \mathrm{~cm}$ [Fig-3].

Table III

Adverse effects in intramuscular testosterone

\begin{tabular}{lc}
\hline Adverse effects & $(\mathrm{n}=70)$ No. $(\%)$ \\
\hline Pubic hair & $10(14.3 \%)$ \\
Genital pigmentation & $0(0 \%)$ \\
Dermatitis & $2(2.9 \%)$ \\
\hline
\end{tabular}

Few adverse effects were noted and among them development of Pubic hair in more common (14.3\%).

\section{Discussion}

Hypospadias is one of the most common congenital anomalies, occurring in approximately 1 in 250 newborns, or roughly 1 in 125 live male births. ${ }^{1}$ Repair of the micro phallic hypospadiac penis can be technically challenging. ${ }^{5}$ In boys with various genitourinary anomalies, including micro penis, hypospadias and epispadias, it has been standard practice to administer exogenous testosterone. ${ }^{7}$ Malik and Liu conducted a survey on pediatric urologists and found that a large proportion of providers use intramuscular testosterone. However, topical testosterone continues to be used by a minority ${ }^{8}$. This study was done to evaluate the efficacy of preoperative intramuscular testosterone therapy for micro phallic hypospadias.

The optimal age for repair of hypospadias is 615 months. ${ }^{9}$ The growth in the penile length takes place for up to 5 years followed by little change until the onset of puberty. ${ }^{2}$ In this study, the age of the participants ranged from 6 to 60 months (5years) where mean age was $34.19 \pm 17.07$ months. In this study the lower limit of age of the patients resembles the age of the patients of the study of Luo et al. ${ }^{10}$ and the upper limit of age of the patients resembles the age of the patients of the study of Ishii et al.. ${ }^{11}$ The debate on age for hormone therapy is ongoing. The rational, behind early hormone therapy, is to correct the hypospadias with surgery at early age, to prevent undue and avoidable psychological stress in infants and parents. ${ }^{5}$

In this study, maximum of cases were posterior and middle type. In the study done by Chalapathi et al. 9 patients had penoscrotal hypospadias, 5 patients had proximal penile hypospadias and 4 patients had distal penile hypospadias out of 26 patients. ${ }^{2}$ Another study by Luo et al. found 14 patients with penoscrotal hypospadias out of 25 patients in their study. ${ }^{10}$ So, in general, severe hypospadias such as penoscrotal hypospadias and proximal hypospadias are seen to be associated with micro phallus.

In this study preoperative testosterone was used in patients with penile length $<3.5 \mathrm{~cm}$ and glans width $<1.4 \mathrm{~cm}$. Penile length was increased up to desired length $(>3.5 \mathrm{~cm})$ in case of 32 patients within 4 weeks. So, no further administration of parenteral 
testosterone was done. In the rest of the 38 patients, desired length was obtained in 8 weeks. So, their parenteral testosterone therapy was stopped. This observation was similar to the study by Gorduza et al. who gave monthly intramuscular injections and stopped when penile length was at or above $35 \mathrm{~mm} .^{12}$

The difference between initial and last measured penile length was $1.32 \mathrm{~cm}$. The penile length increased significantly after eight weeks of intramuscular testosterone therapy as $p<0.05$. This result is quite similar with the result of Ishii et al. where they found $1.01 \mathrm{~cm}$ of alteration of penile length. ${ }^{11}$

It was reported that parenteral administration of testosterone enanthate $(2 \mathrm{mg} / \mathrm{kg})$, once monthly for three months prior to surgery, increased penile length from $2.40 \pm 0.048 \mathrm{~cm}$ to $2.416 \pm 0.045 \mathrm{~cm} .{ }^{14}$

In boys with micro phallic hypospadias, it is difficult to measure stretched penile length especially in proximal cases with ventral curvature and abnormal skin attachment. ${ }^{3}$ Glans size is easy to measure in these cases. So, in this study, the maximum glans width was measured before, during and after the therapy. Before treatment, the mean glans width of 70 patients was $1.09 \pm 0.18 \mathrm{~cm}$. Then, after 8 weeks, the mean became $1.62 \pm 0.01 \mathrm{~cm}$. The glans width increased significantly after eight weeks of intramuscular testosterone therapy as $p<0.05$.

Testosterone has various adverse effects which may limit its application. Adverse effects such as, development of pubic hair, facial hair, acne, bone growth, genital pigmentation and skin reactions, occur. ${ }^{15}$ in this study, three adverse effects, and appearance of pubic hair, genital pigmentation and dermatitis has been considered. The bone growth was not evaluated due to time constrain. None of the patients developed genital pigmentation. Two patients developed dermatitis. The study by Chalapathi et al. reported that one patient in testosterone group suffered from dermatitis. ${ }^{2}$ Appearance of pubic hair is one of the secondary effects of testosterone. Systemic effect of intramuscular testosterone causes fine pubic hair to appear. ${ }^{14}$ In this study, ten patients developed pubic hair. Nerli et al found that fine pubic hair was noted to three children receiving testosterone injection. ${ }^{15}$

A systemic review done by Netto et al. showed greater occurrence of adverse effects associated with topical use of testosterone, such as pigmentation of genitals ( $69 \%$ topical vs $0 \%$ perenteral), appearance of pubic hair $(35.2 \%$ topical vs $11.2 \%$ perenteral) and skin irritation at the site of application (3.8\% vs $0 \%$ perenteral). ${ }^{6}$ The incidence of adverse effects such as genital pigmentation and dermatitis in topical testosterone group may relate to unpredictable absorption and uncontrolled application of testosterone by parents. ${ }^{2}$ Appearance of pubic hair is common adverse effect in both groups, as it is due to systemic effect of testosterone, which is one of the secondary sexual characteristics in male. ${ }^{14}$ These side effects regress after the cessation of testosterone therapy. ${ }^{6}$

\section{Conclusion}

Significant penile growth was observed with less adverse effects after using intramuscular testosterone. Hormone therapy preceding surgical correction of micro phallic hypospadias improves aesthetic and functional qualities of the penis.

\section{References}

1. Baskin LS. Hypospadias. In:Coran AG, Adzick NS, Krummel TM, Laberge JM, Shamberger $\mathrm{RC}$, Caldamone AA, editors. Pediatric surgery, $7^{\text {th }}$ ed. vol.2, Philadelphia: Mosby Elsevier; 2012. p.1531-1553.

2. Chalapathi G, Rao KLN, Chowdhary SK, Narasimhan KL, Samujh R and Mahajan JK. Testosterone Therapy in Microphallic Hypospadias: Topical or Parenteral? Journal of Pediatric Surgery. 2003; 38(2):221-223.

3. Bush NC, DaJusta D, Snodgrass WT. Glans penis width in patients with hypospadias compared to healthy controls. Journal of Pediatric Urology. 2013; 9:1188-1191.

4. Baskin LS. Hypospadias. In: Grosfeld JL, O’Neill JA Jr., Fonkalsrud EW, Coran AG, editors. Pediatric surgery. $6^{\text {th }}$ ed. vol.2, Philadelphia: Mosby Elsevier; 2006. p.1871-1898.

5. Husmann DA. Microphallic hypospadias-the use of human chorionic gonadotropin and testosterone before surgical repair. The Journal of Urology.1999; 162:1440-1441.

6. Netto JMB, Ferrarez CEPF, Leal AAS, Tucci S Jr, Gomes CA, Barroso U Jr. Hormone therapy in hypospadias surgery: A systematic review. Journal of Pediatric Urology. 2013; 9:971-979. 
7. Baskin LS, Sutherland RS, DiSandro MJ, Hayward SW, Lipschutz J and Cunha GR. The effect of testosterone on androgen receptors and human penile growth. The Journal of Urology. 1997; 158:1113-1118.

8. Malik RD, Liu DB. Survey of pediatric urologists on the preoperative use of testosterone in the surgical correction of hypospadias. Journal of Pediatric Urology. 2014; 20:1-4.

9. Zavitsanakis A and Gougoudi E. Timing of elective hypospadias repair. In: Hadidi AT and Azmi AF, editors. Hypospadias Surgery An Illustrated Guide, $1^{\text {st }}$ ed. Germany: Spinger; 2004. p.83-85.

10. Luo CC, Lin JN, Chiu CH, Lo FS. Use of parenteral testosterone prior to hypospadias surgery. Pediatric Surgery International. 2003; 19:82-84.

11. Ishii T, Hayashi M, Suwanal A, Amano N, Hasegawa T. The effect of intramuscular testosterone enanthate treatment on stretched penile length in prepubertal boys with hypospadias. The Journal of Urology. 2010; 76:97-100.

12. Gorduza DB, Gay CL, de Mattos Silva E, Demede D, Hameury F, Berthiller J, et al. Does androgen stimulation prior to hypospadias surgery increase the rate of healing complication? - a preliminary report. Journal of Pediatric Urology. 2011; 7:158-161.

13. Snyder PJ. Androgens. In:Brunton LL, Chabner BA and Knollman BC (eds), Goodman \& Gilman's The Pharmacological Basis of Therapeutics, $12^{\text {th }}$ ed. New York: McGraw Hill Medical; 2011. p.1195-1207.

14. Testosterone cream [Internet]. Texas: Empower Pharma: 2015 [cited 2016 April 11]. Available from: https://empower.pharmacy/drugs/ testosterone-cream.html

15. Nerli RB, Koura A, Prabha V, Reddy M. Comparison of topical versus parenteral testosterone in children with microphallic hypospadias. Pediatric Surgery International. 2009; 25(1):57-59. 